\title{
Milligram per Inhalation
}

National Cancer Institute

\section{Source}

National Cancer Institute. Milligram per Inhalation. NCI Thesaurus. Code C67400.

An inhalation dosing unit equal to the quantity of medicinal substance(s) expressed in

milligrams delivered per a single act of taking in breath. 